\title{
Understanding physical activity intentions among French Canadians with type 2 diabetes: an extension of Ajzen's theory of planned behaviour
}

\author{
François Boudreau ${ }^{1}$ and Gaston Godin*2
}

Address: ${ }^{1}$ Department of Nursing, Université du Québec à Trois-Rivières, G9A 5H7, Canada and ${ }^{2}$ Canada Research Chair on Behaviour and Health, Faculty of Nursing, Laval University, Pavillon Ferdinand-Vandry, 3e étage, 1050 rue de la Médecine, Québec (Québec), G1V 0A6, Canada

Email: François Boudreau - francois.boudreau@uqtr.ca; Gaston Godin* - gaston.godin@fsi.ulaval.ca

* Corresponding author

Published: 16 June 2009

International Journal of Behavioral Nutrition and Physical Activity 2009, 6:35 doi:10.1 186/1479-5868-6-35

This article is available from: http://www.ijbnpa.org/content/6/l/35

(C) 2009 Boudreau and Godin; licensee BioMed Central Ltd.

This is an Open Access article distributed under the terms of the Creative Commons Attribution License (http://creativecommons.org/licenses/by/2.0), which permits unrestricted use, distribution, and reproduction in any medium, provided the original work is properly cited.
Received: 6 February 2009

Accepted: 16 June 2009

\begin{abstract}
Background: Regular physical activity is considered a cornerstone for managing type 2 diabetes. However, in Canada, most individuals with type 2 diabetes do not meet national physical activity recommendations. When designing a theory-based intervention, one should first determine the key determinants of physical activity for this population. Unfortunately, there is a lack of information on this aspect among adults with type 2 diabetes. The purpose of this cross-sectional study is to fill this gap using an extended version of Ajzen's Theory of Planned Behavior (TPB) as reference.
\end{abstract}

Methods: A total of 50I individuals with type 2 diabetes residing in the Province of Quebec (Canada) completed the study. Questionnaires were sent and returned by mail.

Results: Multiple hierarchical regression analyses indicated that TPB variables explained $60 \%$ of the variance in intention. The addition of other psychosocial variables in the model added $7 \%$ of the explained variance. The final model included perceived behavioral control $(\beta=.38, p<.000 \mathrm{I})$, moral norm $(\beta=.29, \mathrm{p}<.000 \mathrm{I})$, and attitude $(\beta=.14, \mathrm{p}<.0 \mathrm{I})$.

Conclusion: The findings suggest that interventions aimed at individuals with type 2 diabetes should ensure that people have the necessary resources to overcome potential obstacles to behavioral performance. Interventions should also favor the development of feelings of personal responsibility to exercise and promote the advantages of exercising for individuals with type 2 diabetes.

\section{Background}

In Canada, considering the increasing incidence of type 2 diabetes [1], it is estimated that this disease and related complications [2] will soon represent an important challenge for health professionals and public health authorities. Fortunately, for almost all individuals with type 2 diabetes, improved glycemic control would be sufficient to prevent or delay micro- and macrovascular complica- tions. This could be accomplished by the practice of regular and moderate physical activity [3]. According to Canadian guidelines, individuals with type 2 diabetes should accumulate at least 150 minutes of moderateintensity aerobic exercise each week, spread over at least three non-consecutive days of the week [4]. It is estimated that Canadians with self-reported diabetes are more likely to be physically inactive (65\%), compared to members of 
the general population (56\%) [5]. Therefore, identifying strategies that facilitate participation in physical activity for individuals with type 2 diabetes represents a major challenge for health educators.

In the field of health promotion and prevention, it is increasingly recognized that the development of effective educational interventions requires an understanding of the phenomenon being studied for a specific population in a given context [6]. Moreover, the selection of theories is an important step in developing interventions [7]. In this regard, social cognitive models can prove helpful in understanding key determinants of a given behavior.

One of the most thoroughly tested social cognitive models is Ajzen's Theory of Planned Behavior (TPB) [8]. It has been applied to understand several health-related behaviors [9], including exercise or physical activity $[10,11]$. A meta-analysis [10] showed that the TPB variables accounted for, on average, $30.4 \%$ of the variance in intentions to exercise. According to the TPB, the proximal determinants of intention to adopt or not to adopt a behavior are attitude, subjective norm and perceived behavioral control with respect to adopting the behavior. Attitude represents an individual's evaluation of the perceived benefits and drawbacks of adopting a given behavior (e.g. "My doing physical activities in my free time during the next month would be good/bad"). Subjective norm reflects the perceived expectations of specific individuals or groups regarding the adoption of a given behavior (e.g. "In your opinion, are the people who are most important to you in favor or not in favor of your regular participation in one or more physical activities in your free time during the next month?"). Lastly, perceived behavioral control is determined by the individual's perception of the presence or absence of resources and opportunities, as well as perceived obstacles and impediments regarding adoption of the target behavior (e.g. "To me, participating in one or more physical activities in my free time during the next month appears difficult/easy"). In addition, each of the TPB variables is defined by a set of salient beliefs. These three sets of beliefs are behavioral beliefs (attitude toward the behavior), normative beliefs (subjective norm), and control beliefs (perceived behavioral control).

Recently, two studies tested the ТРВ [12] to understand physical activity among individuals with type 2 diabetes. White et al. [13] used a cross-sectional design to examine exercise beliefs among Australians with type 2 diabetes or cardiovascular disease $(n=192)$. Multiple regression analyses indicated that exercise beliefs explained $12 \%$ of the variance in behavior. However, White et al. did not report the proportion of variance explained in intention. For their part, Plotnikoff et al. [14] tested the TPB in order to provide guidance for the development of programs aimed at promoting physical activity among Canadians with type $1(n=697)$ or type 2 diabetes $(n=1614)$. In a crosssectional model, the results indicated that $40 \%$ of the variance in intention for those with type 2 diabetes was explained by attitude $(\beta=0.36, \mathrm{p}<0.05)$, subjective norm $(\beta=0.12, \mathrm{p}<0.05)$, and perceived behavioral $(\beta=0.34, \mathrm{p}$ $<0.05)$. Respectively, intention $(\beta=0.23, \mathrm{p}<0.05)$ and perceived behavioral control $(\beta=0.09, \mathrm{p}<0.05)$ explained $8 \%$ of the variance in physical activity (6 months). Unfortunately, Plotnikoff et al. did not identify the beliefs underlying the main variables of the TPB. Therefore, the information needed to develop an intervention is missing.

Past research in the determinants of physical activity suggests that determinants other than those identified in the TPB can contribute to explaining additional portions of variance in intention [15]. In this respect, four determinants must be considered: anticipated regret, moral norm, descriptive norm and past behavior. According to Abraham \& Sheeran [16], anticipated regret "refers to beliefs about whether or not feelings of regret or upset will follow inaction (e.g. 'I would regret it if I did not exercise tomorrow')" (p.496). In the field of physical activity, Abraham \& Sheeran $[16,17]$ observed a correlation of .57 between anticipated regret and intention among a sample of undergraduate students. In a similar study, Conner \& Abraham [18] reported a correlation of .48. Abraham and Sheeran [17] also observed that anticipated regret contributed to a substantial increment in the variance of intention $(5.3 \%)$, after the determinants of the TPB and past behavior were taken into account. More importantly, however, was the demonstration that an intervention designed to highlight anticipated regret towards not exercising significantly enhanced exercise intentions [17]. Thus, it is justified to verify if anticipated regret contributes to the prediction of intention among individuals with type 2 diabetes.

Moral norm measures "feelings of personal obligation towards the adoption of the behavior" [19]. A growing body of research supports the inclusion of this determinant in the prediction of intention [20]. The additional explained variance in intention, after the TPB determinants are considered, is about $4 \%$ [15]. Similar findings are observed in the field of physical activity [21,22]. This determinant could play a significant role in strengthening intentions to exercise among individuals with type 2 diabetes, since most individuals with type 2 diabetes know about the importance of exercising for their health and of their responsibility in this regard [23]. It is thus possible that a recommendation to exercise by a health professional increases feelings of moral obligation to take responsibility for personal health.

Recently, it was recommended that a descriptive norm as a determinant of intention [24] be added. A descriptive 
norm "refer to an individual's belief about how widespread a particular behavior is among referent others" [25]. It is hypothesized that as the perceived prevalence of a given behavior increases, the likelihood of intent to adopt this behavior increases [25]. In a meta-analysis comprising twenty-one tests of the relationship between descriptive norm and intention, the addition of descriptive norm to the prediction of intention, after the TPB determinants had been taken into consideration, led to a significant increment of $5 \%$ in the explained variance [26]. With respect to physical activity, studies among samples of undergraduate students $[27,28]$ and cancer survivors [28] observed that descriptive norm was a significant independent predictor of intention. Therefore, it is appropriate to verify the relevance of descriptive norm among individuals with type 2 diabetes.

Finally, Conner and Armitage [15] showed that, after taking into account the TPB determinants, past behavior explained, on average, a further $7.2 \%$ of the variance in intention. Past behavior was retained on the basis of a meta-analytic review, indicating that it may play an important role in predicting intention to be physically active[29].

\section{Purpose of This Study}

The aim of the present study was twofold: to identify the determinants of intention to participate in leisure-time physical activity among French Canadians with type 2 diabetes and to identify the beliefs underlying the determinants of intention that could be used to develop an intervention. The following hypotheses were formulated based on Ajzen's Theory of Planned Behavior and earlier research: (1) Attitude, subjective norm and perceived behavioral control will constitute significant determinants of physical activity-related intentions; (2) Anticipated regret, moral norm, descriptive norm and past behavior will explain a significant amount of additional variance beyond the direct determinants of the TPB in the prediction of intention.

\section{Methods \\ Participants and Procedure}

A total of 2000 individuals with diabetes (age range 3564 years) were randomly selected from the data sets of the " la Régie de l'assurance maladie du Québec " (Quebec Health Insurance Board). This data source does not differentiate between type 1 and type 2 diabetes. Self-reported questionnaire used in the present study allowed the distinction between these two types of diabetes. Authorization from the "Access to information Commission" was obtained and all study procedures were approved by the University Ethics Committee. A package was mailed to the individuals containing a self-administered questionnaire, return envelope, and cover letter - signed by the investiga- tors - describing the purpose of the survey and requesting the individuals' cooperation. Recipients were advised that their responses would remain confidential and that no name would appear on the questionnaire. One follow-up reminder was sent 10 days after mailing the initial questionnaire. All questionnaires used were in French-language.

Of the 2000 questionnaires mailed, 144 were returned because recipients were not interested in participating in the study, 92 self-reported major physical limitations in terms of physical activity, eight had incorrect addresses, three did not understand French and two died before receiving the questionnaire. Overall, 588 completed questionnaires were received for a participation rate of $33 \%$. Of these, $33(5.6 \%)$ did not answer the question on selfreported diabetes, while 54 (9.7\%) and 501 (90.3\%) were individuals with self-reported type 1 and type 2 diabetes, respectively. For the purpose of our study, only individuals reporting type 2 diabetes were retained.

\section{Variables}

An elicitation study was first conducted to identify modal salient beliefs. Participants $(n=37)$ were individuals with type 2 diabetes aged 35 to 64 years and participating in a four- to five-day health education program on diabetes self-management. Two methods were used to obtain this information: a semi-structured focus group $(n=6)$, where all verbatim statements made by participants were recorded and entered into an electronic database; and an open-ended questionnaire $(n=31)$. The mean age of these 31 participants was 58.2 years $(S D=9.7)$ and $52 \%$ were male. Regardless of the method, participants were asked about: (1) advantages and disadvantages of «participating regularly in one physical activity or more during their free time in the next month "; (2) persons or groups of persons who think that they should or should not perform the behavior in question; and (3) the things that made it easy or difficult for them to practice one or more physical activities on a regular basis. Following each of these procedures, the first author of the current study and a research assistant independently identified the salient beliefs to be used in the questionnaire.

The psychosocial determinants assessed were the variables of the TPB as well as anticipated regret, moral norm and descriptive norm. As recommended by Ajzen \& Fishbein [30], psychosocial determinants were defined in terms of action (participate regularly), target (in one or more physical activities), context (in my free time), and time (during the next six months). Table 1 describes each of the psychosocial variables. The questionnaire was submitted to a test-retest procedure over a two-week period to a subgroup of 30 individuals with type 2 diabetes. The mean age of participants was 58.9 years $(S D=9.8), 33 \%$ were 
Table I: Description of the psychosocial variables and psychometric values Internal consistency* Test-retest reliability $\dagger$

\begin{tabular}{lc}
\hline Variables & Seven-point scales \\
\hline $\begin{array}{l}\text { Intention } \\
\text { - I intend to participate ... }\end{array}$ & Very unlikely/very likely \\
- My plans are to participate regularly ... & Strongly disagree/strongly agree \\
- I estimate that my chances to participate ... & Extremely weak/extremely good \\
\hline Attitude & \\
I think that participating ... would be ... & Very tiresome/very stimulating \\
& Very unenjoyable/very enjoyable \\
& Very dull/very interesting \\
& Very unpleasant/Very pleasant \\
& Very bad/very good \\
& Very useless/very useful \\
& Very Disadvantageous/ \\
very advantageous
\end{tabular}

Subjective norm

- People who are important to me would recommend me to participate ...

- People who are important to me thing I should participate ...

- If you had participate ..., people who are important to you would ...
Strongly disagree/strongly agree

0.83

0.59

Strongly disagree/strongly agree

Strongly disapprove/ strongly approve
Perceived behavioural control

- I feel capable to participate ...

- I am confident that I could ...

- It is completely up to me whether I participate ...

- I am going to have the freedom to participate ...

- For me, participating ...

- How much control do you feel you have over the fact of participating ...
0.76

0.80

0.93

0.64

Behavioural beliefs (ten items)

- If I had participated ..., I would control better my diabetes

Normative beliefs (five items)

- My physician would disapprove-approve that I participate ...

Strongly disapprove/ strongly approve

Strongly disagree/strongly agree Strongly disagree/strongly agree Strongly disagree/strongly agree Strongly disagree/strongly agree

Very difficult/very easy

No control at all/complete control
0.79

0.49
0.86

0.89
Control beliefs (six items)

- If I had a lack of access to facilities, I would participate ...
Very unlikely/very likely

Anticipated regret

- If I did not participate ..., I would regret it/lt would preoccupied me/lt would worry me

Moral Norm

- It is in my principles to participate ...

- I would fell guilty about not to participate ...

Strongly disagree/strongly agree Strongly disagree/strongly agree

0.82

0.73

0.86

0.78

Descriptive norm

- According to you, what proportion of individuals with $0 \%$ to $10 \%, 11 \%$ to $20 \%, 21 \%$ to $29 \%$, etc. diabetes participate...?

Strongly disagree/strongly agree

0.86

Note. Internal consistency was reported as * Cronbach's alpha coefficient for variables of 3 items or more and $\ddagger$ Spearman's correlation coefficient for variables of 2 items. $\dagger=$ Intraclass correlation coefficient. 
male and 33\% had completed postsecondary education. Test-retest intraclass correlation coefficients and the Cronbach's alpha coefficients were verified and are reported in Table 1.

Past behavior was assessed as follows: "How often have you participated in one or more physical activities lasting 20 to 30 minutes per session during your free time in the last three months?" Response choices offered were $1=$ never; $2=$ less than once a month; $3=$ two or three times a month; $4=$ once a week; $5=$ twice a week; $6=$ three times a week; and 7 = four times a week. This method of assessing behavior is based on previous validated studies [31,32].

Age, gender, education and BMI were also assessed. Based on respondents' self-reported weight $(\mathrm{kg})$ and height $(\mathrm{m})$, BMI was calculated as weight $(\mathrm{kg}) /$ height $(\mathrm{m}){ }^{2}$ The weight classification recommended by the WHO Expert Consultation on Obesity was used [33]; BMI between $25.0 \mathrm{~kg} / \mathrm{m}^{2}$ and $29.9 \mathrm{~kg} / \mathrm{m}^{2}$ are considered as overweight and $\mathrm{BMI}$ of $30.0 \mathrm{~kg} / \mathrm{m}^{2}$ or greater indicates obesity.

\section{Statistical Analysis}

Given that there were fewer than 5\% missing data related to the dependent variable intention and/or psychosocial predictors and the non-significant result in MCAR (missing completely at random) test $\left(\chi^{2}=296.7, p=0.89\right)$, missing data were replaced by the mean substitution procedure [34]. A descriptive analysis was first performed. Second, a Pearson product-moment correlation matrix was analyzed to examine the interrelationships between the TPB determinants and additional variables. A hierarchical regression analysis was then conducted in which intention was regressed on the TPB determinants (Step 1). Thereafter, anticipated regret, moral norm and descriptive norm (Step 2), past behavior (Step 3), and age, gender, education and BMI (Step 4) were included. To remain in the final regression equation, a given variable had to reach the standard statistical significance level $(p<.05)$ and, based on the squared semi-partial correlation, its additional contribution explained the variance needed to account for at least $1 \%$ of variance.

Subsequently, von Haeften's et al. [35] guidelines were applied to identify critical beliefs to be targeted for a behavior change intervention. Thus, for the TPB determinants contributing independently to the prediction of intention, the Pearson product-moment correlation matrix was analyzed: (1) to verify if belief-based measures were associated with their respective main constructs (i.e., attitude-behavioral beliefs $[\Sigma \mathrm{b} / \mathrm{n}]$, subjective norm-normative beliefs $[\Sigma n / n]$, perceived behavioral control-control beliefs $[\Sigma \mathrm{c} / \mathrm{n}]$ ); (2) to identify key beliefs significantly correlated with intention. Then, within each belief-based measure, significant key beliefs were entered in a regression analysis to identify those making an independent contribution to the prediction of intention. As a final step, all of the significant beliefs within a belief-based measure that made an independent contribution to the prediction of intention were entered into a final regression. SPSS version 12.0 statistical software was used for all analyses.

\section{Results}

\section{Descriptive Statistics and Correlation Matrix}

The mean age of participants was 56.5 years $(S D=6.5)$, $43 \%$ were male and $26 \%$ had completed postsecondary education. Mean scores and standard deviations of psychosocial and external variables are presented in Table 2. Generally, the means of psychosocial variables were slightly positive, suggesting that participants in this study had a positive predisposition towards the regular practice of physical activity. The mean score for past behavior was $4.1 \pm 2.2$, indicating that, on average, participants were active about once a week during the previous three months.

The matrix of correlation coefficients between intention and its determinants indicated that intention was positively correlated with all variables with the exception of age $(\mathrm{r}=.05, \mathrm{p}=.15)$, gender $(\mathrm{r}=.01, \mathrm{p}=.42)$, education $(\mathrm{r}=.05, \mathrm{p}=.14)$, and BMI $(\mathrm{r}=-.03, \mathrm{p}=.25)$. Because their $p$ value was above .20 , gender and BMI were not retained in subsequent analyses.

\section{Regression Analysis}

A hierarchical regression analysis showed that attitude ( $\beta$ $=.27, \mathrm{p}<.0001)$, subjective norm $(\beta=.09, \mathrm{p}<.05)$ and perceived behavioral control $(\beta=.52, \mathrm{p}<.0001)$ accounted for $59.7 \%$ of the variance in intention $(\mathrm{F}(3,497)=245.5, \mathrm{p}<.0001)($ Table 3$)$. The addition of anticipated regret $(\beta=.08, \mathrm{p}<.05)$, moral norm $(\beta=.31$, $\mathrm{p}<.0001)$, and descriptive norm $(\beta=.03$, ns) added $7 \%$ of the variance explained in intention $(\Delta \mathrm{F}(3,494)=34.83$, $\mathrm{p}<.0001)$; attitude $(\beta=.15, \mathrm{p}<.0001)$ and perceived behavioral control $(\beta=.41, \mathrm{p}<.0001)$ were also significant, whereas subjective norm did not reach the significance level.

The addition of past behavior was statistically significant $(\Delta \mathrm{F}(1,493)=8.4, \mathrm{p}<.005)$ but attitude $(\beta=.14, \mathrm{p}<$ $.0001)$, perceived behavioral control $(\beta=.38, \mathrm{p}<.0001)$, anticipated regret $(\beta=.08, \mathrm{p}<.05)$ and moral norm $(\beta=$ $.29, \mathrm{p}<.0001)$ remained additional significant determinants. However, the single contribution of anticipated regret and past behavior was lower than $1 \%$; thus, they were not kept in the final model. None of the demographic variables made a significant contribution. In summary, attitude, perceived behavioral control and moral 
Table 2: Correlation matrix of the variables

\begin{tabular}{|c|c|c|c|c|c|c|c|c|c|c|c|c|c|c|c|}
\hline & INT & ATT & SN & PBC & BB & NB & $C B$ & $\mathrm{DN}$ & $M N$ & $A R$ & PB & AGE & EDU & GEN & BMI \\
\hline Mean & 5.54 & 5.98 & 6.12 & 5.63 & 5.74 & 6.34 & 5.43 & 4.37 & 5.45 & 5.44 & 4.06 & 56.48 & 2.07 & 1.57 & 36.29 \\
\hline St. Dev. & 1.42 & 1.07 & 1.05 & 1.26 & .83 & .90 & 1.19 & 1.95 & 1.47 & 1.47 & 2.19 & 6.45 & .85 & .49 & 8.24 \\
\hline INT & - & & & & & & & & & & & & & & \\
\hline ATT & $.65 \ddagger$ & - & & & & & & & & & & & & & \\
\hline SN & $.45 \ddagger$ & $.46 \ddagger$ & - & & & & & & & & & & & & \\
\hline PBC & $.74 \ddagger$ & $.65 \ddagger$ & $.47 \ddagger$ & - & & & & & & & & & & & \\
\hline BB & $.34 \ddagger$ & $.39 \ddagger$ & $.43 \ddagger$ & $.37 \ddagger$ & - & & & & & & & & & & \\
\hline NB & $.45 \ddagger$ & $.50 \ddagger$ & $.73 \ddagger$ & $.58 \ddagger$ & $.51 \ddagger$ & - & & & & & & & & & \\
\hline$C B$ & $.71 \ddagger$ & $.65 \ddagger$ & $.46 \ddagger$ & $.80 \ddagger$ & $.36 \ddagger$ & $.51 \ddagger$ & - & & & & & & & & \\
\hline $\mathrm{DN}$ & $.28 \ddagger$ & $.23 \ddagger$ & $.23 \ddagger$ & $.22 \ddagger$ & $.09 \ddagger$ & $.17 \ddagger$ & $.23 \ddagger$ & - & & & & & & & \\
\hline MN & $.69 \ddagger$ & $.59 \ddagger$ & $.46 \ddagger$ & $.59 \ddagger$ & $.32 \ddagger$ & $.43 \ddagger$ & $.60 \ddagger$ & $.32 \ddagger$ & - & & & & & & \\
\hline$A R$ & $.54 \ddagger$ & $.48 \ddagger$ & $.40 \ddagger$ & $.49 \ddagger$ & $.30 \neq$ & $.36 \ddagger$ & $.57 \ddagger$ & $.25 \ddagger$ & $.57 \ddagger$ & - & & & & & \\
\hline PB & $.47 \ddagger$ & $.40 \ddagger$ & $.18 \ddagger$ & $.48 \ddagger$ & $.08^{*}$ & $.18 \ddagger$ & $.45 \ddagger$ & $.21 \ddagger$ & $.40 \ddagger$ & $.29 \ddagger$ & - & & & & \\
\hline AGE & .05 & -.02 & .00 & $.08^{*}$ & .01 & .02 & .04 & .06 & .06 & .07 & .03 & - & & & \\
\hline EDUa & .05 & $.08^{*}$ & .01 & .04 & $.12 * *$ & $.10 *$ & $.08^{*}$ & -.06 & .01 & .01 & -.04 & $-.10 *$ & - & & \\
\hline GENb & .01 & .03 & $-.08^{*}$ & -.01 & -.01 & $-.09 *$ & .00 & .03 & -.04 & -.01 & .04 & $-.08^{*}$ & -.07 & - & \\
\hline BMI & -.03 & -.06 & .07 & -.05 & $.14 \dagger$ & $.10 *$ & -.08 & -.06 & -.06 & -.07 & $-.16 \ddagger$ & $-.12 \dagger$ & .05 & $-.1 I^{* *}$ & - \\
\hline
\end{tabular}

Note. INT = intention. ATT = attitude. $\mathbf{S N}=$ subjective norm. $\mathbf{P B C}=$ perceived behavioural control. $\mathbf{B B}=$ behavioural beliefs. $\mathbf{N B}=$ normative beliefs. $\mathbf{C B}=$ control beliefs. $\mathbf{D N}=$ descriptive norm. $\mathbf{M R}=$ moral norm. $\mathbf{A R}=$ anticipated regret. $\mathbf{P B}=$ past behaviour. $\mathbf{G E N}=$ gender. $\mathbf{E D U}=$ education. $\mathbf{B M I}=$ body mass index.

$\mathrm{a}=\mathrm{I}$ (less than high school), 2 (completed high school), 3 (completed college), 4 (completed university).

$\mathrm{b}=\mathrm{I}$ (male), 2 (female).

$* \mathrm{p}<.05$.

$* * \mathrm{p}<.01$.

$+\mathrm{p}<.005$

$\ddagger p<.0001$.

norm were the determinants of intention, explaining $67.3 \%$ of its variance.

\section{Key Beliefs Underlying Intention}

Given that attitude and perceived behavioral control were found to be significant determinants of intention, their underlying beliefs were analyzed to identify critical targets for intervention. As can be seen in Table 2, correlational analyses showed that the behavioral and control beliefs were significantly correlated with attitude $(\mathrm{r}=.39, \mathrm{p}<$ $0.0001)$ and perceived behavioral control $(\mathrm{r}=.80, \mathrm{p}<$ $0.0001)$, respectively. In Table 4, individual correlational analyses showed that eight of the ten behavioral beliefs were significantly correlated with intention ( $\mathrm{r}=.15$ to .34). These significant behavioral beliefs were then entered into a regression analysis and only "makes me feel good mentally" ( $\beta=.18)$ and "improves my fitness level" $(\beta=.14)$ contributed independently to the prediction of intention. Similarly, as can be seen in Table 4, all six control beliefs were found to have a significant relationship with intention $(r=.32$ to .63$)$. Regression analysis showed that five of these beliefs contributed independently to the prediction of intention, that is "financial constraints" $(\beta=$ .26), "health problems" $(\beta=.21)$, "lacking time" $(\beta=$ $.17)$, "lacking access to facilities" $(\beta=.13)$, and "working schedule" $(\beta=.12)$.
Finally, to identify the critical targets for an intervention, the seven individual belief predictors identified above were entered into a final regression analysis. Figure 1 illustrates the final model containing the six critical beliefs explaining $54 \%$ of variance in intention to participate regularly in leisure-time physical activity: (1) "financial constraints" $(\beta=.25)$; (2) "health problems" $(\beta=.20)$; (3) "lacking time" ( $\beta=.17)$; (4) "makes me feel good mentally" ( $\beta=.14)$; (5) "lacking access to facilities" $(\beta=.14)$; and, (6) "working schedule" $(\beta=.11)$.

\section{Discussion}

Using the TPB and additional determinants, the purpose of this study was to predict and explain the intention of individuals with type 2 diabetes to engage in physical activity on a regular basis. Results indicate that $67 \%$ of the variability of intention may be explained, in decreasing order of importance, by perception of control over behavior, moral norm and attitude. According to criteria established by Cohen [36], the percentage of explained variance of intention corresponds to strong effect size $\left(f^{2} \geq .35\right)$.

To our knowledge, in the context of the TPB, few studies like this one have been published on individuals with type 2 diabetes, making it difficult to place results obtained in perspective. Nonetheless, as mentioned in the introduction of this study, Plotnikoff et al. [14] found that attitude $(\beta=0.36, \mathrm{p}<$ 
Table 3: Summary of the hierarchical regression analysis of intention

\begin{tabular}{|c|c|c|c|c|}
\hline Variable & $\beta$ & $\mathrm{R}^{2}$ & Change in $\mathrm{R}^{2}$ & $s r^{2}$ \\
\hline \multicolumn{5}{|l|}{ Step I } \\
\hline Attitude & $.27 \ddagger$ & & & .04 \\
\hline Subjective norm & $.08^{*}$ & & & .004 \\
\hline Perceived Behavioural Control & $.52 \ddagger$ & .597 & - & .15 \\
\hline \multicolumn{5}{|l|}{ Step 2} \\
\hline Attitude & $.15 \ddagger$ & & & .01 \\
\hline Subjective norm & .01 & & & .000 \\
\hline Perceived Behavioural Control & $.41 \ddagger$ & & & .08 \\
\hline Descriptive Norm & .03 & & & .001 \\
\hline Moral norm & $.31 \ddagger$ & & & .05 \\
\hline Anticipated regret & $.08^{*}$ & .667 & .07 & .004 \\
\hline \multicolumn{5}{|l|}{ Step 3} \\
\hline Attitude & $.14 \ddagger$ & & & .01 \\
\hline Subjective norm & .02 & & & .000 \\
\hline Perceived Behavioural Control & $.38 \ddagger$ & & & .06 \\
\hline Descriptive Norm & .02 & & & .000 \\
\hline Moral norm & $.29 \ddagger$ & & & .04 \\
\hline Anticipated regret & $.08^{*}$ & & & .003 \\
\hline Past Behaviour & $.09 \dagger$ & .673 & .006 & .005 \\
\hline \multicolumn{5}{|l|}{ Step 4} \\
\hline Attitude & $.14 \ddagger$ & & & .01 \\
\hline Subjective norm & .02 & & & .000 \\
\hline Perceived Behavioural Control & $.38 \ddagger$ & & & .06 \\
\hline Descriptive Norm & .02 & & & .000 \\
\hline Moral norm & $.29 \ddagger$ & & & .04 \\
\hline Anticipated regret & $.08^{*}$ & & & .003 \\
\hline Past Behaviour & $.09 \dagger$ & & & .005 \\
\hline Age & .00 & & & .000 \\
\hline Education & .02 & .674 & .001 & .000 \\
\hline
\end{tabular}

Note. $\beta=$ standardized regression coefficients. $s r^{2}=$ squared semipartial correlation.

$* \mathrm{p}<.05 . \dagger \mathrm{p}<.005 . \neq \mathrm{p}<.0001$.

$0.05)$, subjective norm $(\beta=0.12, \mathrm{p}<0.05)$ and perception of behavioural control $(\beta=0.34, \mathrm{p}<0.05)$ explained $40 \%$ of the variance of intention to engage in physical activity among Canadians with type 2 diabetes. Other studies conducted in the field of physical activity among patients suffering from heart disease [37-39] and patients having survived cancer [40-42], revealed that $24 \%$ to $51 \%$ and $38 \%$ to $66 \%$ of the variance in intention was explained, respectively. This means that in the course of this study, results obtained explaining intention compare favorably with research carried out on symptomatic clientele. Therefore, it might be suggested that psychosocial determinants identified in this study could be used to develop an educational intervention aimed at encouraging the practice of physical activity among individuals with type 2 diabetes. The intervention would target persons exhibiting little or no motivation to adopt the practice of regular physical activity. As is now acknowledged in the scientific literature $[43,44]$, it is advisable to distinguish a motivational phase (weak intention) from a postmotivational phase (strong intention) during the development of an educational intervention.

When considering developing an educational intervention for individuals with type 2 diabetes, particular atten- tion should be paid to the perception of control over behavior. Indeed, this determinant has the greatest relative importance in the modeling of intention. In other terms, the decision of persons with type 2 diabetes to engage in physical activity on a regular basis is based primarily on the perceived ease of practicing such behavior. These results are congruent with observations reported for studies carried out on symptomatic populations $[38,40,42,45,46]$. By and large, according to Ajzen [47], the greater the relative contribution of a determinant, the greater the probability of a change to this determinant influencing intention and behavior. Thus, from a practical perspective, when the goal consists of fostering the adoption of regular physical activity among individuals with a low intention, prioritizing educational messages aimed at eliminating perceived obstacles might be suggested. Given this, five of the six obstacles identified in this study might be the target of such messages. In this respect, strategies recommended by Bandura [48], such as actively experiencing control, verbal persuasion, etc., could prove useful in achieving the above goal.

Moral norm was the second determinant of relative importance in the modeling of intention, in conformity 
Table 4: Mean and standard deviation of beliefs, and correlation coefficient with intention

\begin{tabular}{llll}
\hline Beliefs & M & SD & $r$ \\
\hline Behavioural beliefs & & & \\
$\quad$ Physical fitness & 6.34 & 1.22 & $.33^{*}$ \\
Weight control & 618 & 1.43 & $.27^{*}$ \\
Diabetes control & 6.32 & 1.29 & $.3 I^{*}$ \\
Heart health & 6.36 & 1.24 & $.33^{*}$ \\
Time management & 5.69 & 1.65 & $.16^{*}$ \\
Improve global health & 6.40 & 1.24 & $.32^{*}$ \\
Improve mental health & 6.06 & 1.40 & $.34^{*}$ \\
Lacking time to do something else & 4.21 & 2.10 & .01 \\
$\quad$ Risk of hypoglycaemia & 4.19 & 2.20 & .00 \\
Improve insulin action & 5.56 & 1.87 & $.15^{*}$ \\
Control beliefs & & & \\
Bad or poor weather & 5.00 & 1.79 & $.53^{*}$ \\
Lacking time & 5.23 & 1.60 & $.61^{*}$ \\
Financial constraints & 5.36 & 1.68 & $.63^{*}$ \\
Lacking access to facilities & 5.25 & 1.67 & $.62^{*}$ \\
Health problems & 5.11 & 1.66 & $.63^{*}$ \\
Working schedule & 6.71 & 1.78 & $.32^{*}$ \\
\hline
\end{tabular}

20 participants had missing data on one or several items $*=\mathrm{p}<.001$

with one of the hypotheses advanced. To date, use of the moral norm among symptomatic populations had been rather limited. In fact, to our knowledge, only one study has explored this determinant among individuals suffering from heart disease and results pointed to a non-significant contribution to the modeling of intention [37]. In the case of individuals with type 2 diabetes, the results of this study suggest that the feeling of moral obligation to engage in physical activities on a regular basis is a significant component of the decision to take action. From a practical standpoint, instilling greater motivation to regu- larly practice physical activities through the development of an educational message based on moral norm poses a dual challenge. First, contrary to perceived behavioral control for which the TPB offers guidelines on the definition of content of educational messages by targeting control beliefs, guidelines defining content targeting moral norm are rather limited. Indeed, in his theory of interpersonal behavior, Triandis [49] provides a rather vague idea of this construct without specifying its nature or dimensions (quoted by Blondeau et al. [50]). Likewise, Jackson et al. [22] also point to the challenge of defining the content of educational messages within acceptable ethical boundaries. For example, when promoting the regular practice of physical activity, developing a message based on «victim-blaming » would be contrary to ethical principles.

Based on the preceding, one avenue to explore to ensure the proper development of an educational message is the premise that moral norms are rooted in social norms, and when these norms become strongly anchored within a person's psyche, they have an impact on behavior irrespective of the immediate social context [20]. Concretely, since health professionals treating individuals suffering from diabetes often recommend physical activity [23], it is plausible that such recommendations might become interiorized within a certain time. Thus, the feeling of moral obligation to adopt the behavior might emerge, regardless of the immediate social context.

Although the contribution of attitude was moderate in the modeling of intention, it warrants consideration, nonetheless, in the development of an intervention. Research conducted among individuals with heart disease also

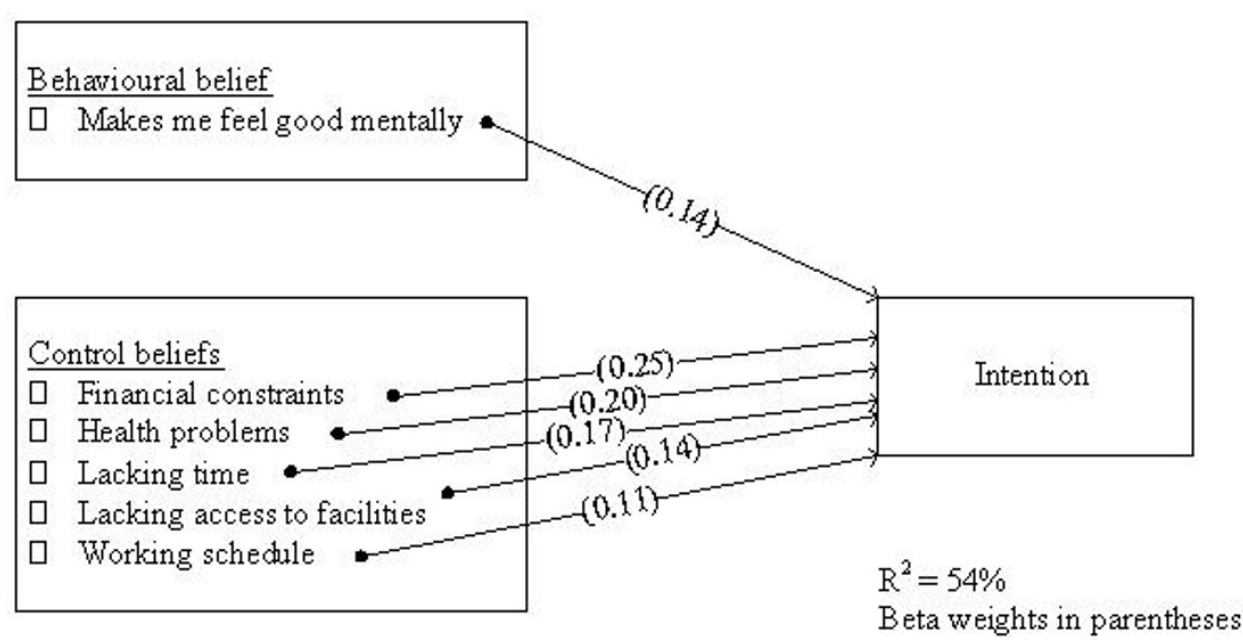

Figure I

Critical belief targets for an intervention to increase intention to participate in leisure-time physical activity of individuals with type 2 diabetes. 
Table 5: Summary of the key findings regarding factors to take into account with respect to physical activity promotion in French Canadians with type 2 diabetes

\begin{tabular}{lll}
\hline Factors & Intervention objectives & Intervention targets \\
\hline Perceived behavioural control & $\begin{array}{l}\text { Develop strategies to overcome regular physical } \\
\text { activity barriers. }\end{array}$ & $\begin{array}{l}\text {-Financial constraints } \\
\text {-Health problems } \\
\text {-Lacking time }\end{array}$ \\
& & -Lacking access to facilities \\
Moral Norm & $\begin{array}{l}\text { Develop a sense of moral obligation to engage in } \\
\text { regular physical activity. }\end{array}$ & - Testimonials from health professionals to highlight the \\
Attitude & Identify positive outcomes related to regular & importance of regular physical activity on glycemic control \\
& physical activity. & -Mental health
\end{tabular}

reported a moderate but significant contribution of this determinant in the modeling of intention $[38,39]$. On the other hand, based on results observed for Canadians with type 2 diabetes [14] and different types of cancer [45,5154], a more important contribution of attitude was reported. In this study, the moderate contribution of attitude may be explained by the fact that the participants were well aware of the advantages of regular physical activity associated with a disease such as type 2 diabetes. A review of the scores recorded on the attitude scale (scale of 1 to7) for participants with a weak $(\mathrm{M}=4.94)$ or strong $(M=6.34)$ (data not shown) intention tends to support the explanation offered. This acknowledgement of an understanding of the beneficial effects of physical activity among individuals with type 2 diabetes has also been observed elsewhere $[13,23,55]$.

To develop a positive attitude towards regular physical activity, educational messages might possibly be developed to briefly remind individuals of the benefits of physical activity from a psychological perspective. Indeed, among the behavioral beliefs indentified in this study that messages might explore, only psychological wellbeing proved significant in the modeling of intention. As has been demonstrated by Fishbein et al. [56], the transition from a given behavioral belief of « somewhat positive » to " very positive " may result in a significant impact on intention to adopt a given behavior.

Likewise, as reported in other studies on physical activity, the determinants of anticipated regret $[17,57]$ and past behavior [37-39] proved significant in the modeling of intention. From a practical standpoint, however, and given their marginal contribution $(<1 \%)$ to variance explained by intention, we do not consider it relevant to develop educational messages based on either determinant. Descriptive norm, on the other hand was not significant in the modeling of intention. Several factors may explain this result. First, according to Rimel \& Real [25], the greater the prevalence of a behavior within a given group, the greater the probability that said behavior will be adopted by its members in response to the prevailing norm. Yet, in this study, it was estimated that only $41 \%$ to $50 \%$ of individuals with type 2 diabetes engaged in physical activity on a regular basis. This prevalence might be insufficient to create a favorable descriptive norm. Then again, the use of one item alone to measure this construct could explain the result obtained. Finally, it is also possible that the average age $(56.5 \pm 6.5$ years $)$ of participants in this study might explain the non-significant contribution of descriptive norm, insofar as adults of a certain age are less likely to be swayed by this form of social pressure than younger individuals [26].

In retrospect, although the results of this study suggest avenues to explore for the development of educational messages to encourage regular physical activity among individuals with type 2 diabetes certain limitations warrant attention. First, caution should be exercised before generalization of the results to other individuals of the same age range with type 2 diabetes for two reasons: a) the response rate was low at $33 \%$; and $b$ ) the proportion of men and women did not correspond to the reference Canadian population. In our sample more women than men participated. Nonetheless, our results are in agreement with previous studies of physical activity based on the TPB. For instance, considering only the TPB variables, Plotnikoff et al. showed among a representative sample of individuals with type 2 diabetes living in Alberta, Canada, results similar to those of the present study (see Table 3 ). A second limitation is that the participants in the study were possibly more interested in the subject of the study (practicing physical activities) than non-participants. A third limitation resides in the use of self-reported measurement as an indicator of practicing physical activities. However, the measurement was validated [31,32] and deemed pertinent within the context of an independent evaluation. A fourth limitation consists of the cross sectional nature of the study; intention was the outcome variable instead of prospective behavior. Although it is generally acknowledged in the field of physical activity that intention is an important determinant of future 
behavior[29], it remains to be determined if intention is an important and significant determinant of behavior for this population.

\section{Conclusion}

This study identified three psychosocial determinants that explain more than two thirds of the intention to engage in physical activity on a regular basis among individuals with type 2 diabetes. A summary of these key determinants is presented in Table 5 in order to develop interventions aimed at increasing the motivation of individuals with type 2 diabetes to regularly practice physical activities.

\section{Competing interests}

The authors declare that they have no competing interests.

\section{Authors' contributions}

FB and GG conceived the study design. FB carried out the study and drafted the manuscript. GG helped with data analysis and data interpretation, and provided a critical review of the manuscript. Both authors approved the final version of the manuscript.

\section{Acknowledgements}

The authors would like to thank Léo-Daniel Lambert for his collaboration in the analysis of data.

The authors acknowledge the financial support of the Quebec Diabetes Association.

\section{References}

I. Lipscombe LL, Hux JE: Trends in diabetes prevalence, incidence, and mortality in Ontario, Canada 1995-2005: a population-based study. Lancet 2007, 369:750-756.

2. Chaturvedi $\mathrm{N}$ : The burden of diabetes and its complications: Trends and implications for intervention. Diabetes Res Clin Pract. 2007, 76 Suppl I:S3-SI2.

3. Boulé NG, Haddad E, Kenny GP, Wells GA, Sigal RJ: Effects of exercise on glycemic control and body mass in type 2 diabetes mellitus: A meta-analysis of controlled clinical trials. JAMA 200I, 286: $1218-1227$

4. Canadian Diabetes Association Clinical Practice Guideline Expert Committee (CDA): Canadian Diabetes Association 2003 clinical practice guidelines for the prevention and management of diabetes in Canada. Can J Diabetes 2003, 27(Suppl 2): I- I 52.

5. Health Canada: Diabetes in Canada. Second edition. Ottawa Ontario; 2002:1-78.

6. Bartholomew LK, Parcel GS, Kok G: Intervention mapping: A process for developing theory and evidence-based health education programs. Health Educ Behav 1998, 25:545-563.

7. Kok G, Schaalma H, Ruiter RAC, Van Empelen P, Brug J: Intervention mapping: protocol for applying health psychology theory to prevention programmes. J Health Psychol 2004, 9:85-98.

8. Armitage C], Conner M: Efficacy of the theory of planned behaviour: A meta-analytic review. Br J Soc Psychol 200I, 40:47I-499.

9. Godin G, Kok G: The theory of planned behavior: a review of its applications to health-related behaviors. Am J Health Promot 1996, I I:87-98.

10. Downs DS, Hausenblas HA: The theories of reasoned action and planned behavior applied to exercise: A meta-analytic update. J Phys Act Health 2005, 2:76.

II. Hausenblas HA, Carron AV, Mack DE: Application of the theories of reasoned action and planned behavior to exercise behavior: A meta-analysis. J Sport Exerc Psychol 1997, I 9:36-5 I.
12. Ajzen I: The theory of planned behavior. Organ Behav Hum Decis Process 1991, 50:I79-211.

13. White KM, Terry DJ, Troup C, Rempel LA: Behavioral, normative and control beliefs underlying low-fat dietary and regular physical activity behaviors for adults diagnosed with type $\mathbf{2}$ diabetes and/or cardiovascular disease. Psychol Health Med 2007, I 2:485-494.

14. Plotnikoff RC, Lippke S, Courneya K, Birkett N, Sigal R: Physical activity and diabetes: An application of the theory of planned behaviour to explain physical activity for Type I and Type 2 diabetes in an adult population sample. Psychol Health 2008.

15. Conner M, Armitage C): Extending the theory of planned behavior: $A$ review and avenues for further research. J Appl Soc Psychol 1998, 28: |429-|464.

16. Abraham C, Sheeran P: Acting on intentions: the role of anticipated regret. Br J Soc Psychol 2003, 42:495-5II.

17. Abraham C, Sheeran P: Deciding to exercise: the role of anticipated regret. Br J Health Psychol 2004, 9:269-278.

18. Conner M, Abraham C: Conscientiousness and the theory of planned behavior: Toward a more complete model of the antecedents of intentions and behavior. Pers Soc Psychol Bull 200I, 27:I547-I56I.

19. Godin G, Sheeran P, Conner M, Germain M, Blondeau D, Gagne C, Beaulieu D, Naccache $H$ : Factors explaining the intention to give blood among the general population. Vox Sang 2005, 89: 140-149.

20. Manstead ASR: The role of moral norm in the attitude-behavior relation Edited by: Terry DJ, Hogg MA. Mahwah, NJ: Lawrence Erlbaum Associates; 2000: II-30.

21. Godin G, Conner M, Sheeran P: Bridging the intention-behaviour 'gap': the role of moral norm. Br J Soc Psychol 2005, 44:497-512.

22. Jackson C, Smith RA, Conner M: Applying an extended version of the theory of planned behaviour to physical activity. J Sports Sci 2003, 2 I: I 19-I33.

23. Morrato EH, Hill JO, Wyatt HR, Ghushchyan V, Sullivan PW: Are health care professionals advising patients with diabetes or at risk for developing diabetes to exercise more? Diabetes Care 2006, 29:543-548.

24. Courneya KS, Conner M, Rhodes RE: Effects of different measurement scales on the variability and predictive validity of the "two-component" model of the theory of planned behavior in the exercise domain. Psychol Health 2006, 2 I:557-570.

25. Rimal RN, Real K: Understanding the influence of perceived norms on behaviors. Commun Theory 2003, 13:184-203.

26. Rivis A, Sheeran P: Descriptive norms as an additional predictor in the theory of planned behaviour: a meta-analysis. Curr Psychol 2003, 22:218-233.

27. Rhodes RE, Blanchard CM, Matheson DH: A multicomponent model of the theory of planned behaviour. Br J Health Psychol 2006, I I:I I9-137.

28. Rhodes RE, Courneya KS: Investigating multiple components of attitude, subjective norm, and perceived control: An examination of the theory of planned behaviour in the exercise domain. Br J Soc Psychol 2003, 42: I 29-I 46.

29. Hagger MS, Chatzisarantis NLD, Biddle SJH: A meta-analytic review of the theories of reasoned action and planned behavior in physical activity: predictive validity and the contribution of additional variables. J Sport Exerc Psychol 2002, 24:3-32.

30. Ajzen I: Understanding attitudes and predicting social behavior Englewood Cliffs, Nj: Prentice-Hall; 1980.

31. Gionet NJ, Godin G: Self-reported exercise behavior of employees: A validity study. J Occup Med 1989, 3 I:969-973.

32. Godin G, Jobin J, Bouillon J: Assessment of leisure time exercise behavior by self-report: a concurrent validity study. Can J Public Health 1986, 77:359-362.

33. World Health Organization: Obesity: preventing and managing the global epidemic Geneva: World Health Organization; 2000.

34. Tabachnick BG, Fidell LS: Using multivariate statistics Boston; Toronto: Pearson/Allyn and Bacon; 2007.

35. von Haeften I, Fishbein M, Kasprzyk D, Montano D: Analyzing data to obtain information to design targeted interventions. Psychol Health Med 2001, 6:151-164.

36. Cohen J: A power primer. Psychol Bull I992, I I 2:155-I59. 
37. Godin G, Valois P, Jobin J, Ross A: Prediction of intention to exercise of individuals who have suffered from coronary heart disease. J Clin Psychol 1991, 47:762-772.

38. Blanchard CM, Courneya KS, Rodgers WM, Daub B, Knapik G: Determinants of exercise intention and behavior during and after phase 2 cardiac rehabilitation: an application of theory of planned behavior. Rehabil Psychol 2002, 47:308-323.

39. Blanchard CM, Courneya KS, Rodgers WM, Fraser SN, Murray TC, Daub B, Black B: Is the theory of planned behavior a useful framework for understanding exercise adherence during phase II cardiac rehabilitation? J Cardiopulm Rehabil 2003, 23:29-39.

40. Hunt-Shanks TT, Blanchard CM, Baker F, Hann D, Roberts CS, McDonald J, Livingston M, Witt C, Ruiterman J, Ampela R, Kaw OCK: Exercise use as complementary therapy among breast and prostate cancer survivors receiving active treatment: Examination of exercise intention. Integr Cancer Ther 2006, 5: I09-1 I6.

4I. Jones LW, Courneya KS, Vallance JK, Ladha AB, Mant MJ, Belch AR, Reiman T: Understanding the determinants of exercise intentions in multiple myeloma cancer survivors: an application of the theory of planned behavior. Cancer Nurs 2006, 29:167-I75.

42. Karvinen K, Courneya K, Campbell K, Pearcey R, Dundas G, Capstick $\mathrm{V}$, Tonkin K: Correlates of exercise motivation and behavior in a population-based sample of endometrial cancer survivors: An application of the theory of planned behavior. Int J Behav Nutr Phys Act 2007, 4:21.

43. Sniehotta FF, Schwarzer R, Scholz U, Schuz B: Action planning and coping planning for long-term lifestyle change: Theory and assessment. Eur J Soc Psychol 2005, 35:565-576.

44. Fishbein M, Yzer MC: Using theory to design effective health behavior interventions. Commun Theory 2003, I3:164-183.

45. Blanchard CM, Courneya KS, Rodgers WM, Murnaghan DM: Determinants of exercise intention and behavior in survivors of breast and prostate cancer: An application of the theory of planned behavior. Cancer Nurs 2002, 25:88-95.

46. Jones LW, Guill B, Keir ST, Carter K, Friedman HS, Bigner DD, Reardon DA: Using the theory of planned behavior to understand the determinants of exercise intention in patients diagnosed with primary brain cancer. Psychooncology 2007, 16:232-240.

47. Ajzen I: Behavioral interventions based on the theory of planned behavior. [http://people.umass.edu/aizen/pdf/tpb.inter vention.pdf].

48. Bandura A: Social foundations of thought and action: a social cognitive theory Englewood Cliffs, N.J.: Prentice-Hall; 1986.

49. Triandis HC: Values, attitudes and interpersonal behavior. In Nebraska Symposium on Motivation Beliefs, Attitudes and Values Volume I. Edited by: Page MM. Lincoln, NE: University of Nebraska Press; 1980:195-259.

50. Blondeau D, Godin G, Gagné C, Martineau I: Do ethical principles explain moral norm? A test for consent to organ donation. Journal of Applied Biobehavioral Research 2004, 9:230-243.

51. Courneya KS, Friedenreich CM: Determinants of exercise during colorectal cancer treatment: an application of the theory of planned behavior. Oncol Nurs Forum 1997, 24:1715-1723.

52. Courneya KS, Friedenreich CM: Utility of the theory of planned behavior for understanding exercise during breast cancer treatment. Psychooncology 1999, 8:112-122.

53. Courneya KS, Friedenreich CM, Arthur K, Bobick TM: Understanding exercise motivation in colorectal cancer patients: A prospective study using the theory of planned behavior. Rehabil Psychol 1999, 44:68-84.

54. Courneya KS, Keats MR, Turner R: Social cognitive determinants of hospital-based exercise in cancer patients following highdose chemotherapy and bone marrow transplantation. Int J Behav Med 2000, 7:189-203.

55. Plotnikoff RC, Brez S, Brunet S: Are exercise social-cognitive factors and behaviours different for adults with diabetes? A randomized community sample. Psychol Health Med 2003, 8:465-47I.

56. Fishbein M, Von Haeften I, Appleyard J: The role of theory in developing effective interventions: implications from Project SAFER. Psychol Health Med 2001, 6:223-238.

57. Conner M, Abraham C: Conscientiousness and the theory of planned behavior: Toward a more complete model of the antecedents of intentious behavior. Pers Soc Psychol Bull 200I, 27:|547-|56|.
Publish with Biomed Central and every scientist can read your work free of charge

"BioMed Central will be the most significant development for disseminating the results of biomedical research in our lifetime. "

Sir Paul Nurse, Cancer Research UK

Your research papers will be:

- available free of charge to the entire biomedical community

- peer reviewed and published immediately upon acceptance

- cited in PubMed and archived on PubMed Central

- yours - you keep the copyright

Submit your manuscript here:

http://www.biomedcentral.com/info/publishing_adv.asp
BioMedcentral 